\title{
LA SUCESIÓN EN LAS UNIONES DE HECHO
}

\section{DOMESTIC PARTNERSHIP AND INHERITANCE RIGHTS}

\author{
Mario Castillo Freyre ${ }^{1}$
}

\section{RESUMEN}

En el presente artículo el autor comenta-desde una perspectiva constitucional y civil - los alcances de la Ley $N^{\circ} 30007$, a fin de reconocer derechos sucesorios entre los miembros de uniones de hecho. De igual manera, se analizan los problemas prácticos que conllevan la aplicación de la citada Ley. Entre ellos, el autor no es del parecer que la concurrencia de concubinos determine una concurrencia de derechos sucesorios. En consecuencia, en caso de pluralidad de uniones de hecho, y en caso de concurrencia de concubinos con vocación hereditaria, los tribunales deberian hacer prevalecer aquella unión de hecho más estable y que se parezca más a la unión matrimonial.

Palabras Claves: Unión de hecho, concubino, vocación hereditaria, heredero, causante.

\begin{abstract}
In this article, the author comments -from constitutional and civil perspectives- the scope of Law $N^{o} 30007$, whose purpose is to recognize inheritance rights between domestic partners. Similarly, the paper analyzes the practical problems faced when applying such Law. Among them, the author does not believe that the mere fact of concubines concurring is sufficient to determine inheritance rights. Consequently, in case of multiple domestic partnerships, and in case of several cohabitants having hereditary rights, the courts should make prevail the most stable domestic partnership and the one that most resembles a marital union.
\end{abstract}

Key Words: Domestic partnership, Cohabitants, Right to inherit, heir/heiress, deceased persons.

\footnotetext{
1 Mario Castillo Freyre, Magíster y Doctor en Derecho por la Pontificia Universidad Católica del Perú; abogado en ejercicio; socio del Estudio que lleva su nombre; Miembro de Número de la Academia Peruana de Derecho; profesor de Derecho Civil, en la categoría de Principal en las Facultades de Derecho de la Universidad Femenina del Sagrado Corazón y de la Pontificia Universidad Católica del Perú. Director de las Colecciones Biblioteca de Arbitraje y Biblioteca de Derecho de su Estudio.

Fecha de recepción : 31 de julio de 2013.

Fecha de aceptación : 05 de agosto de 2013.
} 


\section{ANTECEDENTES}

El miércoles 17 de abril de 2013 fue publicada en el diario oficial "El Peruano" la Ley $\mathrm{N}^{\circ}$ 30007, que modifica los artículos 326, 724, 816 y 2030 del Código Civil; además del inciso 4 del artículo 425 y el artículo 831 del Código Procesal Civil; y el inciso 4 del artículo 39 de la Ley $\mathrm{N}^{\circ} 26662$, a fin de reconocer derechos sucesorios entre los miembros de uniones de hecho.

La Constitución de 1979, en el Título I relativo a los Derechos y deberes fundamentales de la persona, Capítulo II, De la Familia, artículo 9, dio un paso muy importante al establecer en dicho artículo, lo siguiente:

Artículo $9^{\circ}$ - La unión estable de un varón y una mujer, libres de impedimento matrimonial, que forman un hogar de hecho por el tiempo y en las condiciones que señala la ley, da lugar a una sociedad de bienes que se sujeta al régimen de la sociedad de gananciales en cuanto es aplicable.

Como no podía ser de otra manera, el Código Civil de 1984 recogió el concepto del artículo 9 de la Constitución Política de 1979. Lo hizo en su artículo 326, norma de texto siguiente:

Artículo 326.- "La unión de hecho, voluntariamente realizada y mantenida por un varón y una mujer, libres de impedimento matrimonial, para alcanzar finalidades $y$ cumplir deberes semejantes a los del matrimonio, origina una sociedad de bienes que se sujeta al régimen de sociedad de gananciales, en cuanto le fuere aplicable, siempre que dicha unión haya durado por lo menos dos años continuos.

La posesión constante de estado a partir de fecha aproximada puede probarse con cualquiera de los medios admitidos por la ley procesal, siempre que exista un principio de pruebaescrita.

La unión de hecho termina por muerte, ausencia, mutuo acuerdo o decisión unilateral. En este último caso, el juez puede conceder, a elección del abandonado, una cantidad de dinero por concepto de indemnización o una pensión de alimentos, además de los derechos que le correspondan de conformidad con el régimen de sociedad de gananciales. 
Tratándose de la unión de hecho que no reúna las condiciones señaladas en este artículo, el interesado tiene expedita, en su caso, la acción de enriquecimiento indebido.

Asimismo, el principio contenido en el artículo 326 fue reiterado por el artículo 5 de la Constitución Política del Perú, promulgada el 29 de diciembre de 1993 y que entró en vigencia el 31 de diciembre de ese año, con la siguiente redacción:

Artículo $5^{\circ}$.- La unión estable de un varón y una mujer, libres de impedimento matrimonial, que forman un hogar de hecho, da lugar a una comunidad de bienes sujeta al régimen de la sociedad de gananciales en cuanto sea aplicable.

Como puede apreciarse, la tendencia legislativa con respecto a la protección del patrimonio de los miembros de las uniones de hecho, ha sido invariable desde la Constitución de 1979 (la misma que entró en vigencia el 28 de julio de 1980).

El propósito del constituyente de 1979 fue muy positivo, en la medida que era consciente de los múltiples abusos que se cometían, generalmente de parte de los hombres en perjuicio de las mujeres, cuando una pareja convivía durante varios años, pero ella no estaba casada.

Como en la mayoría de situaciones el hombre era quien trabajaba y la mujer se ocupaba de la casa, el hombre adquiría los bienes (empezando por el inmueble en el que convivían y siguiendo con las demás pertenencias), a nombre propio, de manera tal que cuando se rompía esa convivencia, el varón se hacía de todo ese patrimonio de la manera más fácil, en la medida de que casi todos los bienes importantes se hallaban a su nombre.

Y esta situación era muy injusta, en la medida que dicho patrimonio había sido hecho por el esfuerzo común de ambos convivientes, ya que la labor de la mujer en el cuidado de la casa y de los hijos no se estaba considerando para estos efectos.

Es verdad que la norma constitucional de 1979 ya tiene una antigüedad de 34 años y que la situación de la mujer en el terreno laboral ha avanzado mucho en el Perú, no obstante lo cual ella sigue siendo desventajosa con relación al hombre debido a múltiples razones, por todos conocidas. 
Por lo demás, fue un acierto que la Constitución Política de 1993 acogiera similar principio y que el Código Civil de 1984 diese una regulación pormenorizada sobre el particular en el ya citado artículo 326 .

A mi generación le correspondió estudiar Derecho precisamente en el tránsito del Código de 1936 al de 1984 y, de discutir en los salones de clase sobre los temas trascendentes que implicaron las modificaciones de un cuerpo normativo a otro.

En ese sentido, recuerdo muy bien que una de las materias que ya se planteaba en las aulas universitarias a mediados de los años ochenta del siglo pasado, era el relativo a si el artículo 326 del Código Civil, si bien había seguido la norma constitucional de 1979, no habría sido lo suficientemente de avanzada al no reconocer derechos sucesorios al concubino.

Recuerdo también interesantes discusiones con mis compañeros de clase y con algunos profesores en este sentido.

En aquella época, el razonamiento fundamental que giraba en torno al tema, era el relativo a si debían o no heredar entre sí los concubinos o miembros de uniones de hecho. $Y$ recuerdo también que el argumento central que se esgrimía para negar esta posibilidad era aquél que sostenía que si se legislase en este sentido, prácticamente no existirían mayores diferencias entre el matrimonio y la unión de hecho, razón por la cual se desincentivaría a las parejas para contraer matrimonio, y ellas optarían por convivir, ya que su patrimonio iba a estar resguardado tanto por un régimen similar al de la sociedad de gananciales (artículo 326 del Código Civil), como por un régimen hereditario en el cual los concubinos heredaran recíprocamente, tal como si fueran cónyuges.

Confieso que en aquella época yo era de los partidarios de que no se concediese derechos sucesorios recíprocos a los concubinos; pero hoy, transcurrido tanto tiempo, he cambiado de parecer y estimo que ese criterio del que formé parte no hacía sino perjudicar los derechos de un grupo numeroso de personas que no se encontraban allí por otra circunstancia que no fuese por el devenir de la vida, ya que uno no necesariamente escoge cómo va a vivir sino que en el camino uno va ordenándose de la mano con la realidad.

En ese sentido, fue una grata sorpresa para mí el leer la Ley $N^{\circ} 30007$, de abril del presente año, pues al fin se otorgaban derechos sucesorios entre los miembros de las uniones de hecho. 
Por lo demás, dicha norma legal sólo efectúa este reconocimiento entre parejas heterosexuales, ya que en su artículo 1, que define su objeto, se señala que "la presente Ley tiene por objeto reconocer derechos sucesorios entre un varón y una mujer, libres de impedimento matrimonial, que conforman una unión de hecho".

Asimismo, para la procedencia de derechos sucesorios, el artículo 2 establece que "para que la unión de hecho dé lugar a derechos sucesorios es requisito que reúna las condiciones señaladas en el artículo 326 del Código Civil y se encuentre vigente al momento del fallecimiento de cualquiera de sus miembros".

En ese sentido, el referido artículo 326 señala claramente cuáles son los requisitos para que la unión de hecho sea reconocida para efectos de una sociedad de gananciales, los mismos que se podrían enumerar del siguiente modo:

a) La unión de hecho tiene que ser voluntaria.

b) Sus integrantes deben ser un varón y una mujer.

c) Deben estar libres de impedimento matrimonial.

d) La unión debe realizarse para alcanzar finalidades y cumplir deberes semejantes a los del matrimonio.

e) Debe haber durado al menos dos años continuos.

Esto significa que el propio Código Civil excluye a todo aquél que no se encuentre dentro de los requisitos mencionados, de modo tal que, a título de ejemplo, podemos decir que no producirá los efectos de una sociedad de gananciales la unión de hecho entre una mujer soltera y un hombre casado.

En este caso, la única sociedad de gananciales que existiría (si es que no hubiera pacto de separación de patrimonios) sería la de ese hombre casado consu esposa.

Y esto es lógico, en la medida que el Código Civil auspicia el matrimonio como modelo fundamental de familia en el Perú, independientemente de que no cabe duda de que existen otros modelos de familia distintos al matrimonial, los mismos que no constituyen objeto de análisis en estas páginas.

En otras palabras, para que se presente el supuesto del artículo 326 del Código Civil, sólo podría existir un reparo de orden moral (el convivir sin estar casados), mas no uno de orden legal. 

Distinto es el caso del supuesto contenido en el segundo párrafo de la Ley, ya que el mismo pasa por la situación en la cual al momento de la muerte de uno de los integrantes de la unión de hecho, ésta no se encontrara inscrita en el Registro Personal.

En tal sentido, resulta evidente que el trámite de reconocimiento de la unión de hecho deberá ser efectuado por el conviviente supérstite, con vocación hereditaria.

Es oportuno señalar que en la inmensa mayoría de casos los convivientes no registran sus uniones de hecho en vida, fundamentalmente por una cuestión de orden moral y social. Es claro que en las relaciones sociales cualquiera prefiere presentarse como "esposo o esposa de alguien" (sin serlo) o incluso como la "pareja" de alguien (tal vez creando cierta ambigüedad sobre su estado civil), que presentarse como el conviviente de alguien; y no sólo eso, sino que además, se trataría de un conviviente erga omnes, pues figuraría inscrito con tal condición nada menos que en Registros Públicos.

Es en virtud de tales consideraciones que me temo que la nueva Ley no va a lograr que un número muy grande de personas que se encuentren conviviendo en uniones de hecho, reconozcan y registren en vida tal situación. Así las cosas, el reconocimiento de la unión de hecho, para que tenga efectos sucesorios, fundamentalmente será hecho por el conviviente supérstite en la vía judicial.

\subsection{Modificación del artículo 326 del Código Civil y modificaciones indirectas a diversas normas de este cuerpo normativo}

Hasta este punto nos hemos limitado a comentar cuáles son los alcances de la Ley $\mathrm{N}^{\circ} 30007$ en lo que respecta a sus consideraciones generales, pero, como es evidente, dicha norma ha introducido modificaciones importantes en una serie de artículos del Código Civil.

El primero de ellos es naturalmente, el artículo 326, precepto al que se le ha incorporado (agregado) un último párrafo, de texto siguiente:

Las uniones de hecho que reúnan las condiciones señaladas en el presente articulo producen, respecto de sus miembros, derechos y deberes sucesorios, similares a los del matrimonio, por lo que las disposiciones contenidas en los 
artículos 725, 727, 730, 731, 732, 822, 823, 824 y 825 del Código Civil ${ }^{2}$ se aplican al integrante sobreviviente de la unión de hecho en los mismos términos en que se aplicarían al cónyuge. ${ }^{3}$

\title{
Tales normas son las referidas a la sucesión del cónyuge.
}

\section{De esta forma, el artículo 725 deberá entenderse como que el que tiene hijos, otros descendientes, o cónyuge o miembro de unión de hecho, puede disponer libremente hasta del tercio de sus bienes.}

\author{
En el mismo sentido, el artículo 727 deberá entenderse como que el que no \\ tiene cónyuge, miembro de una unión de hecho, ni parientes de los indicados \\ en los artículos 725 y 726, tiene la libre disposición de la totalidad de sus \\ bienes.
}

2 Artículo $725^{\circ}$.- El que tiene hijos u otros descendientes, o cónyuge, puede disponer libremente hasta del tercio de sus bienes.

Artículo $727^{\circ}$.-El que no tiene cónyuge ni parientes de los indicados en los artículos 725 y 726 , tiene la libre disposición de la totalidad de sus bienes.

Artículo $730^{\circ}$.- La legítima del cónyuge es independiente del derecho que le corresponde por concepto de gananciales provenientes de la liquidación de la sociedad de bienes del matrimonio.

Artículo $731^{\circ}$.- Cuando el cónyuge sobreviviente concurra con otros herederos y sus derechos por concepto de legítima y gananciales no alcanzaren el valor necesario para que le sea adjudicada la casa-habitación en que existió el hogar conyugal, dicho cónyuge podrá optar por el derecho de habitación en forma vitalicia y gratuita sobre la referida casa. Este derecho recae sobre la diferencia existente entre el valor del bien y el de sus derechos por concepto de legítima y gananciales.

La diferencia de valor afectará la cuota de libre disposición del causante y, si fuere necesario, la reservada a los demás herederos en proporción a los derechos hereditarios de éstos.

En su caso, los otros bienes se dividen entre los demás herederos, con exclusión del cónyuge sobreviviente.

Artículo $732^{\circ}$.- Si en el caso del artículo 731 el cónyuge sobreviviente no estuviere en situación económica que le permita sostener los gastos de la casa-habitación, podrá, con autorización judicial, darla en arrendamiento, percibir para sí la renta y ejercer sobre la diferencia existente entre el valor del bien y el de sus derechos por concepto de legítima y gananciales los demás derechos inherentes al usufructuario. Si se extingue el arrendamiento, el cónyuge sobreviviente podrá readquirir a su sola voluntad el derecho de habitación a que se refiere el artículo 731.

Mientras esté afectado por los derechos de habitación o de usufructo, en su caso, la casa-habitación tendrá la condición legal de patrimonio familiar.

Si el cónyuge sobreviviente contrae nuevo matrimonio, vive en concubinato o muere, los derechos que le son concedidos en este artículo y en el artículo 731 se extinguen, quedando expedita la partición del bien. También se extinguen tales derechos cuando el cónyuge sobreviviente renuncia a ellos.

El artículo 732 fue complementado por la Sexta Disposición Final del Código Procesal Civil (Resolución Ministerial $n .^{\circ} 010-$ 93-JUS, que aprobó el Texto Único Ordenado del Código Procesal Civil, promulgado mediante Decreto Legislativo n. ${ }^{\circ} 768$ y que incluye las normas del Decreto Legislativo $n .^{\circ} 767$, Decreto Ley $n .^{\circ} 25940$ y Decreto Ley $n .^{\circ} 25869 ;$ publicada en el Diario Oficial «El Peruano» el día 22 de abril de 1993), que señala lo siguiente: Salvo que este Código establezca un proceso especial, se tramitan como proceso no contencioso las solicitudes o autorizaciones del Código Civil a que se refieren los Artículos: (...) 732 (...).

3 ${ }^{3}$ Artículo $822^{\circ}$.- El cónyuge que concurre con hijos o con otros descendientes del causante, hereda una parte igual a la de un hijo.

Artículo $823^{\circ}$.- En los casos del artículo 822 el cónyuge puede optar por el usufructo de la tercera parte de la herencia, salvo que hubiere obtenido los derechos que le conceden los artículos 731 y 732.

Artículo $824^{\circ}$.- El cónyuge que concurra con los padres o con otros ascendientes del causante, hereda una parte igual a la de uno de ellos.

Artículo $825^{\circ}$.-Si el causante no ha dejado descendientes ni ascendientes con derecho a heredar, la herencia corresponde al cónyuge sobreviviente. 
De otro lado, el artículo 730 deberá ser leído de la siguiente manera: la legítima del cónyuge o miembro de una unión de hecho es independiente del derecho que le corresponde por concepto de gananciales provenientes de la liquidación de la sociedad de bienes del matrimonio o de la unión de hecho, respectivamente.

Por su parte, el artículo 731 debería ser interpretado de la siguiente manera:

Cuando el cónyuge o miembro de unión de hecho sobreviviente concurra con otros herederos y sus derechos por concepto de legitima y gananciales no alcanzaren el valor necesario para que le sea adjudicada la casahabitación en que existió el hogar conyugal o convivencial, dicho cónyuge o miembro de unión de hecho podrá optar por el derecho de habitación en forma vitalicia y gratuita sobre la referida casa. Este derecho recae sobre la diferencia existente entre el valor del bien y el de sus derechos por concepto de legitima y gananciales.

La diferencia de valor afectará la cuota de libre disposición del causante $y$, si fuere necesario, la reservada a los demás herederos en proporción a los derechos hereditarios de éstos.

En su caso, los otros bienes se dividen entre los demás herederos, con exclusión del cónyuge o miembro de unión dehecho sobreviviente».

Por otra parte, el texto del artículo 732 se deberá entender de la siguiente manera:

Si en el caso del artículo 731 el cónyuge o miembro de una unión de hecho sobreviviente no estuviere en situación económica que le permita sostener los gastos de la casa-habitación, podrá, con autorización judicial, darla en arrendamiento, percibir para sí la renta y ejercer sobre la diferencia existente entre el valor del bien $y$ el de sus derechos por concepto de legitima y gananciales los demás derechos inherentes al usufructuario. Si se extingue el arrendamiento, el cónyuge o miembro de una unión de hecho sobreviviente podrá readquirir a su sola voluntad el derecho de habitación a que se refiere el artículo 731. 
Mientras esté afectado por los derechos de habitación o de usufructo, en su caso, la casa-habitación tendrá la condición legal de patrimonio familiar.

Si el cónyuge sobreviviente contrae nuevo matrimonio, vive en concubinato o muere, los derechos que le son concedidos en este artículo y en el artículo 731 se extinguen, quedando expedita la partición del bien. También se extinguen tales derechos cuando el cónyuge sobreviviente renuncia a ellos. Lo propio ocurrirá si el miembro de una unión de hecho vive en concubinato, muere o renuncia a tales derechos.

El artículo 822 del Código Civil, deberá entenderse de la siguiente manera: "El cónyuge o miembro de una unión de hecho que concurre con hijos o con otros descendientes del causante, hereda una parte igual a la de un hijo".

Por su parte, el artículo 823 deberá entenderse así: “En los casos del artículo 822 el cónyuge o miembro de una unión de hecho puede optar por el usufructo de la tercera parte de la herencia, salvo que hubiere obtenido los derechos que le conceden los artículos 731 y 732 ".

En tanto el artículo 824 se entenderá de la siguiente manera: "El cónyuge o miembro de una unión de hecho que concurra con los padres o con otros ascendientes del causante, hereda una parte igual a la de uno de ellos".

Finalmente, el artículo 825 del Código Civil se entenderá de la siguiente manera: "Si el causante o miembro de una unión de hecho no ha dejado descendientes ni ascendientes con derecho a heredar, la herencia corresponde al cónyuge sobreviviente".

Como puede apreciarse, si bien es cierto el artículo 4 de la Ley N. ${ }^{\circ} 30007$, al incorporar un párrafo al artículo 326 del Código Civil, no ha modificado expresamente los nueve artículos que ahí menciona, es evidente que en ellos se ha producido una modificación indirecta, ya que las normas citadas no se van a aplicar solamente al cónyuge, sino también al integrante de una unión de hecho, si fuese el caso.

\subsection{El supuesto de los herederos forzosos}

Como sabemos, el artículo 723 del Código Civil establece que "La legítima constituye la parte de la herencia de la que no puede disponer libremente el testador cuando tiene herederos forzosos". 
En ese sentido, el artículo 724 del Código Civil le ha dado a los miembros de las uniones de hecho, el carácter de herederos forzosos y ha dispuesto que ellos se verán beneficiados con lo dispuesto por el artículo 725, que establece el tercio de libre disposición para el causante que tenga hijos $\mathrm{u}$ otros ascendientes, o cónyuge o sea miembro de una unión de hecho.

Estas normas tienen un valioso contenido, en la medida que se está protegiendo la calidad sucesoria del miembro de una unión de hecho, tanto como se venía protegiendo la del cónyuge.

\subsection{Legítima versus condición de heredero}

El artículo 730 del Código Civil subraya que la legítima del cónyuge es independiente de los gananciales que le corresponden por razón de la liquidación de la sociedad de bienes del matrimonio.

Esta norma, ahora también se aplica a los miembros de las uniones de hecho.

\subsection{El derecho a vivir en la casa-habitación}

El artículo 731 antes sólo protegía al cónyuge en el supuesto por él contenido. Ahora también lo hace con respecto al miembro de una unión de hecho.

\subsection{El orden sucesorio en las uniones de hecho}

Al haberse equiparado los derechos sucesorios de los miembros de las uniones de hecho a los del cónyuge, necesariamente se tenía que efectuar una modificación en lo que respecta a los órdenes sucesorios.

Y así se ha hecho al modificar expresamente el artículo 816 del Código Civil, norma que trata acerca de los derechos sucesorios.

El referido artículo hoy tiene el texto siguiente:

Artículo $816^{\circ}$.- Son herederos del primer orden, los hijos y demás descendientes; del segundo orden, los padres y demás ascendientes; del tercer orden, el cónyuge o, en su caso, el integrante sobreviviente de la unión de hecho; del cuarto, quinto $y$ sexto órdenes, respectivamente, los parientes colaterales del segundo, tercer y cuarto grado de consanguinidad. 
El cónyuge o, en su caso, el integrante sobreviviente de la unión de hecho también es heredero en concurrencia con los herederos de los dos primeros órdenes indicados en este articulo.

Esto equivale a que debe entenderse que el Título IV, relativo a la sucesión del cónyuge, artículos $822,823,824$ y 825 , ha sido modificado (como en efecto lo hace la Ley $\mathrm{N}^{\circ} 30007$, artículo 4 , al haber incorporado un último párrafo al artículo 326 del Código Civil), haciendo aplicables todos los preceptos de la sucesión del cónyuge a la sucesión del miembro de una unión de hecho.

\subsection{Ampliación de actos inscribibles en el Registro Personal}

Finalmente, el artículo 7 de la Ley N. 30007 ha dispuesto que serán inscribibles en el Registro Personal "Las uniones de hecho inscritas en vía notarial o reconocidas por vía judicial". Esto, al haber agregado un inciso $10 \mathrm{al}$ referido artículo 2030.

\subsection{Problemas prácticos que conlleva la aplicación de la Ley $\mathbf{N} .^{\circ} 30007$}

En principio, parecería fácil señalar que es miembro de una unión de hecho aquella persona que cumple con los requisitos que siempre estableció el artículo 326 del Código Civil; y que nosotros hemos estudiado en el rubro de antecedentes del presente trabajo.

No cabe duda de que habrá casos en los cuales no ofrecerá dificultad el determinar quién es miembro de una unión de hecho, pero habrá otros en los que el tema sí resultará difícil de explicar, por las siguientes consideraciones.

Resulta claro que nadie que se encuentre unido en matrimonio, podrá hallarse incurso dentro del caso de las uniones de hecho, regulado por el artículo 326 del Código Civil.

Esto no representará dificultad alguna, así como tampoco el que la unión de hecho tenga que ser voluntaria.

Asimismo, el artículo 326 se encarga de establecer con claridad que los integrantes de la unión de hecho deberán ser un varón y una mujer, razón por la cual no resultan aplicables las disposiciones sobre sociedad de gananciales ni sobre derechos hereditarios, a las uniones de hecho entre personas del mismo sexo. 
En otras palabras, los problemas no estarán centrados en los requisitos que hemos indicados con los literales a), b) y c) en el punto 1 de este trabajo.

Advertimos que tales problemas sí podrán presentarse en lo que respecta a los requisitos d) y e). El primero de ellos relativo a que la unión debe realizarse para alcanzar finalidades y cumplir deberes semejantes a los del matrimonio; y el segundo, en el sentido de que ella debe haber durado, al menos, dos años continuos.

Vamos a ocuparnos del primero de tales requisitos.

Cuando la ley hace referencia a que la unión debe realizarse para alcanzar finalidades y cumplir deberes semejantes a los del matrimonio, no cabe duda de que el legislador estuvo pensando en el supuesto de que se trataba de una unión de hecho con carácter de exclusividad, así como el legislador ha entendido que el matrimonio conlleva una situación de exclusividad con respecto a los cónyuges.

Haciendo una analogía, sí se puede decir que el matrimonio en la ley peruana sólo admite la existencia de dos cónyuges (ya que nadie puede estar casado dos veces; es decir, tener más de un cónyuge a la vez); la unión de hecho se plantea en ese mismo sentido, es decir, con la idea de que nadie que se encuentre en una unión de hecho, tenga, a la vez, otra pareja también en unión dehecho.

Pero, de la teoría a la realidad, en este aspecto hay un trecho muy grande, pues sí resulta plenamente posible que haya personas que, a la vez, mantengan más de una unión de hecho.

Es evidente que esas personas no podrían estar casadas con más de una persona, pues el Derecho se lo impediría, pero los hechos, es decir, la realidad factual, no impide que alguien tenga, a la vez, más de una unión de hecho.

Todos, de seguro, conoceremos más de un caso y aquí tendríamos que preguntarnos si resultaría posible que una misma persona tenga diversos regímenes de sociedad de gananciales con, a su vez, diversos concubinos simultáneos.

Esto acarrearía problemas muy serios a efectos de la liquidación de la sociedad de gananciales cuando, por cualquier razón, acabe la unión de hecho, ya que tendríamos que imaginar una liquidación por cada una de esas uniones, y sólo considerar dentro del patrimonio de la sociedad, aquellos 
bienes que fueron adquiridos con el esfuerzo común de la pareja y que, en ese sentido, tengan directa relación con esa sociedad de gananciales, fruto de la vida en común, precisamente, de esa pareja. Menudo problema.

Ésta es una posibilidad, pues la otra sería la de no considerar como sociedad de gananciales, a ninguna de las uniones de hecho existentes, pues podría decirse que en ninguna de esas uniones el miembro de la unión de hecho que sea común a todas ellas, ha tenido la intención de alcanzar finalidades y cumplir deberes semejantes a los del matrimonio, en razón de que -claro está - ha incumplido el deber de fidelidad.

En este último caso, no hablaríamos de un régimen similar al de la sociedad de gananciales, sino de un régimen similar al de la separación de patrimonios, en el cual lo de cada quien, será de cada quien.

Tales consideraciones que pueden tener esta doble interpretación en materia del régimen de sociedad de gananciales, necesariamente van a tener que ser vistas desde una óptica distinta en el caso de la sucesión de los integrantes de las uniones de hecho.

Decimos esto, en razón de que si bien es admisible teóricamente en Derecho, que se puedan liquidar varias sociedades de gananciales paralelas, ${ }^{3}$ no necesariamente resultaría admisible que varios concubinos o miembros de una unión de hecho supérstites al causante, puedan ser equiparados al cónyuge supérstite para efectos sucesorios.

En este último caso, es claro que al no aceptar la ley peruana la existencia de más de un cónyuge a la vez, tampoco podría aceptar que en la sucesión, en el caso de las uniones de hecho, dos o más concubinos supérstites concurran a heredar en el lugar que ocuparía el cónyuge, si fuese el caso.

Es evidente que esta situación nunca se podría presentar cuando alguien hubiera muerto luego de tener sucesivas uniones de hecho en donde todas ellas hayan durado, al menos, dos años continuos.

Decimos esto, en razón de que los derechos sucesorios del concubino supérstite sólo son concedidos al último concubino, es decir, a aquél que mantenía una unión de hecho de al menos dos años continuos, con el causante.

\footnotetext{
${ }^{3}$ Nos referimos a la liquidación de regímenes de sociedades de gananciales paralelas, pues la liquidación de los regímenes sucesorios no resulta tema novedoso.
} 
Ningún concubino anterior tendrá derecho a heredar; esto, más allá de que hubiese formado con cada uno de esos anteriores concubinos, uniones de hecho que generaron regímenes patrimoniales similares al de la sociedad de gananciales.

Lo que corresponderá en estas uniones de hecho y en la última, será liquidar las sociedades de gananciales, pero sólo el último concubino supérstite tendrá derechos hereditarios.

No obstante, como hemos dicho, no estamos refiriéndonos a este caso, sino a aquél en el cual exista una persona que, al momento de su muerte, haya tenido varias uniones de hecho vigentes, y todas ellas con una duración no menor de dos años continuos.

Dicho sea de paso, ello no está prohibido por la ley, pues ésta no prohíbe convivir con varias personas a la vez, cuando no se está casado.

Sólo prohíbe hacerlo cuando se ha contraído matrimonio con alguien.

Pero, si se es soltero, la convivencia múltiple, independientemente de razones de orden moral, es algo legalmente válido.

En ese sentido, y en razón de lo expuesto, no podríamos admitir la sucesión de más de un concubino o miembro de unión de hecho, pues si ése fuese el caso, tal persona no debería ser equiparada al cónyuge supérstite en materia de derechos hereditarios.

Ello sería algo así como una concurrencia de concubinos en materia hereditaria. $^{4}$

En ese sentido, dicha concurrencia de derechos podría ser solucionada solamente de tres maneras:

a) Que hereden, prorrateando sus derechos, todos los concubinos supérstites.

b) Que herede el concubino que acredite haber tenido mayor posesión de estado y cuya situación hubiera tenido mayor similitud a la del matrimonio.

c) Que no herede ninguno de los concubinos.

\footnotetext{
4 Recordemos que el Código Civil regula, en materias absolutamente distintas, otros tipos de concurrencia: la de acreedores de bien inmueble cierto (artículo 1135), la de acreedores de bien mueble cierto (artículo 1136), la concurrencia de arrendatarios (artículo 1670) y la concurrencia de cesionarios (en el lamentablemente derogado artículo 1217).
} 
Ya hemos manifestado nuestro parecer contrario a que la concurrencia de concubinos determine una concurrencia de derechos sucesorios.

Esta situación la consideraríamos contraria a las finalidades de la Ley N. ${ }^{\circ}$ 30007 y estimamos que el Derecho peruano no podría otorgar a varios concubinos supérstites, en conjunto, la posición sucesoria que tendría el cónyuge.

Del mismo modo, entendemos que la existencia de una multiplicidad de concubinos que concurran a reclamar derechos sucesorios, no podría hacer que los tribunales de justicia, por ese solo hecho, estimen que ninguno de ellos podrá acceder al beneficio otorgado por la Ley N. ${ }^{\circ} 30007$.

Esto significa que la sola concurrencia de concubinos o de miembros de uniones de hecho supérstites, no enervará la aplicación de los beneficios contenidos en la citada Ley.

Es así que, admitiendo que el tema resulta altamente opinable, nos permitimos adherir el criterio de que en casos como éstos, los tribunales de justicia sólo deberían otorgar derechos hereditarios a un concubino supérstite.

Pero, creemos que lo expresado requiere de una mayor explicación.

Ante todo, estimamos que sólo podrían ser considerados como miembros de una unión de hecho, en estos casos, quienes en verdad hayan tenido posesión de estado con el causante, que hubiese sido similar a la que se genera con el matrimonio, lo que conlleva necesariamente a tener un hogar en común, con independencia de si se han procreado o no hijos en esa relación.

Decimos esto, pues para tales efectos deben ser rechazadas todas aquellas relaciones que tengan un obvio carácter de eventualidad, vale decir, todas aquellas relaciones en las cuales, haya o no haya habido hijos, no se haya convivido en un hogar común, lo que equivale a decir que no se haya convivido como si estuvieran casados.

Ello significa que las relaciones sexuales o encuentros sexuales esporádicos no califican de manera alguna dentro de los alcances del artículo 326, ni para efectos de un régimen patrimonial similar al de la sociedad de gananciales, $\mathrm{ni}$ para efectos de derechos sucesorios concubinarios. 
Como podrá apreciar el lector, este razonamiento descarta infinidad de relaciones, pues el día sólo tiene 24 horas y, generalmente, no se puede convivir con dos personas a la vez.

Hemos resaltado la palabra generalmente, en la medida de que hay casos excepcionales en donde una persona, mal que bien, podría convivir, aunque sea de manera precaria, con dos o más personas.

Es el típico caso de aquel hombre que desarrolla sus labores en dos ciudades diferentes y que ha constituido uniones de hecho en cada una de ellas.

Este caso es complejo, pues, probablemente pasará similar número de días en cada ciudad viajando realmente por razones laborales.

Éste es el caso más complejo, pues, en verdad cada una de esas uniones se parecería muchísimo a aquélla constituida por el matrimonio y ambas uniones de hecho tendrían carácter estable.

Naturalmente, podríamos pensar en alguna persona más osada y que haya constituido no sólo dos, sino tres o más uniones de hecho con similar carácter, en diversas ciudades o incluso, en la misma ciudad.

No obstante, como podrá apreciar fácilmente el lector, conforme más uniones de hecho existan, si el tiempo se repartiera por igual en cada una de ellas, tales uniones no tendrán parecido alguno con el matrimonio. Se parecerán más bien a encuentros de carácter esporádico.

Entonces, en caso de pluralidad de uniones de hecho, y en caso de concurrencia de concubinos con vocación hereditaria, somos de opinión de que los tribunales deberían hacer prevalecer aquella unión de hecho más estable y que se parezca más a la unión matrimonial.

Es verdad que luego de este análisis podríamos encontrarnos con supuestos en los cuales dos uniones de hecho tengan grandes parecidos con los efectos prácticos de la unión matrimonial. En estos casos, los tribunales de todas maneras tendrían que decidir entre una y otra; $y$, para tal efecto, ensayamos algunos criterios de solución:

a) Se podría preferir la unión más antigua.

Se trata solamente de un orden prelatorio, pero el mismo tendría fundamento, ya que si se tratase de una unión más antigua, sería obvio que hubiese durado más tiempo que la otra unión de hecho, pues ambas habrían terminado con la muerte del concubino-causante. 
b) Se podría pensar en aquella unión de hecho en donde se hubiesen procreado más hijos.

Sin embargo, no creemos que ésta deba ser la solución, pues el tener o no tener hijos no depende de falta de afecto (ni siquiera de que el mismo esté presente). Se puede querer mucho a una persona con la cual uno no tenga hijos.

Es en razón de tales consideraciones que descartaríamos este criterio.

c) Se podría tomar en cuenta el criterio de la buena fe.

De acuerdo a este criterio, sólo deberían entrar en juego aquellas uniones de hecho que compartan las características del matrimonio, y que hayan partido de la buena fe del concubino supérstite, es decir, que cuando se iniciaron dichas uniones de hecho, el concubino supérstite no haya conocido que el concubino ahora fallecido, era parte de otra unión de hecho.

Sin duda, si aplicáramos este criterio, siempre entraría en juego el concubino de la unión de hecho más antigua, disputando el lugar de preferencia con los demás concubinos de buena fe.

No obstante, también descartaríamos este criterio de preferencia, en razón a que es muy difícil probar la buena fe $y$, fundamentalmente, porque no existe norma legal alguna que prohíba iniciar una unión de hecho con alguien que es miembro de otra unión de hecho y que -incluso - la mantenga en paralelo con la segunda.

En razón de lo expuesto, nos parece que el criterio de antigüedad de la unión de hecho debería primar a efectos de preferir al concubino supérstite para concederle derechos hereditarios; ello, naturalmente, asumiendo que todos esos concubinos deberían tener una situación de igualdad de preferencia por parte del miembro de la unión de hecho que hubiere fallecido y que constituya el causante de cuya sucesión estemos hablando.

Es en razón de esta probanza, que la Ley $\mathrm{N}^{\circ} 30007$, en su artículo 8, ha modificado el inciso 4 del artículo 425 del Texto Único Ordenado del Código Procesal Civil, cuando señala que debe acompañarse a la demanda "la prueba de la calidad de heredero, cónyuge o, en su caso, de integrante sobreviviente 
de la unión de hecho, curador de bienes, administrador de bienes comunes, albacea, o del título con que actúe el demandante, salvo que tal calidad sea materia del conflicto de intereses, y en el caso del procurador oficioso...".

Eso significa que a la demanda judicial para ser declarado heredero, el concubino supérstite deberá acompañar el título que acredite su condición de integrante sobreviviente de la unión de hecho.

No cabe duda de que el caso más sencillo sería aquél en que se acompañe a la solicitud, la constancia de inscripción de la unión de hecho en el Registro Personal, conforme a la modificación incorporada por el artículo 9 de la Ley N. ${ }^{\circ} 30007$ al artículo 831 del Texto Único Ordenado del Código Procesal Civil.

No obstante, el tener registrada la unión de hecho en el Registro Personal no es, en absoluto, algo definitivo.

Decimos esto, en la medida de que bien podría estar inscrita una unión de hecho en el Registro Personal y haber fenecido la unión de hecho en razón de la separación de los concubinos, a pesar de lo cual continúe inscrita dicha unión en el Registro Personal.

Y si éste fuera el caso y se produjera la muerte de uno de los concubinos, es obvio que los demás herederos o el nuevo miembro de una unión de hecho que cumpla con los requisitos señalados por el artículo 326 del Código Civil, podrán hacer valer sus derechos; en el primer caso, a efectos de no compartir la masa hereditaria, con quien tiene la unión de hecho inscrita en el Registro Personal (pero que hoy carece del derecho a heredar); y en el segundo, para ocupar el lugar de esa persona en la sucesión del concubino.

Lo expresado significa que si bien es importante que las uniones de hecho puedan estar inscritas en el Registro Personal, a efectos de la contratación con los concubinos $\mathrm{y}$, sobre todo, para la disposición de bienes comunes, al existir entre ellos un régimen similar al de la sociedad de gananciales, ello no será definitivo ni para efectos de tal régimen patrimonial (pues, la sociedad habría podido fenecer en razón de la desaparición de la unión de hecho); ni mucho menos para efectos sucesorios, pues como hemos visto, es plenamente atacable y discutible la calidad de heredero del concubino inscrito en el Registro Personal, no sólo por haberlo dejado de ser, sino porque pudiera haber otra persona que también ostentara la calidad de concubino y que, como hemos visto en este trabajo, pueda discutir con éxito tal condición en los tribunales y ser preferida en prelación de derechos sucesorios por sobre aquel 
concubino que tenía inscrita la unión de hecho en el Registro Personal al momento de la muerte del concubino-causante.

\subsection{Normas complementarias}

La Ley $\mathrm{N}^{\circ} 30007$ también establece en su artículo 10, la modificación de los artículos 35, 38 y del inciso 4 del artículo 39 de la Ley $N^{\circ} 26662$, Ley de Competencia Notarial en Asuntos No-Contenciosos. continuación:

Dichas normas han quedado con los textos que se consignan a Artículo 35 .- Solicitud.- La comprobación de testamentos se solicita mediante petición escrita que suscribirá:

1. Quien por su vinculo familiar con el causante se considere heredero forzoso o legal, incluido el integrante sobreviviente de la unión de hecho reconocida conforme aley;

2. Quien se considere instituido heredero voluntario olegatario, $y$;

3. Quien sea acreedor del testador o del presunto sucesor.

Artículo $38^{\circ}$.- Procedencia.- La solicitud será presentada por cualquiera de los interesados a que alude el artículo 815 del Código Civil, o por el integrante sobreviviente de la unión de hecho reconocida conforme a ley, ante el notario del lugar del último domicilio del causante.

Artículo 39'.-Requisitos.- La solicitud debe incluir:

[...]

4. Partida de matrimonio o la inscripción en el Registro Personal de la declaración de la unión de hecho, adjuntándose, según sea el caso, el testimonio de la escritura pública o la copia certificada de la sentencia judicial firme;

[...].

Lima, junio del 2013 


\section{REFERENCIAS}

Ley No 30007 - "Ley que modifica los artículos 326, 724, 816 y 2030 del Código Civil, el inciso 4 del artículo 425 y el artículo 831 del Código Procesal Civil y los artículos 35, 38 y el inciso 4 del artículo 39 de la Ley 26662, a fin de reconocer derechos sucesorios entre los miembros de uniones de hecho", publicado el 17 de abril de 2013 en el Diario Oficial "El Peruano".

Ley No 26662, "Ley de Competencia Notarial en Asuntos No Contenciosos", publicado en el Diario Oficial “El Peruano”, el 22 de setiembre de 1996. 
